$\begin{array}{ll}\text { Research Square } & \text { Preprints are preliminary reports that have not undergone peer review. } \\ \text { They should not be considered conclusive, used to inform clinical practice, } \\ \text { or referenced by the media as validated information. }\end{array}$

\title{
Yearly Trends In The Prevalence of Ocular Traumas And The Effects of Covid-19: A Nationwide Population-Based Study of Korean Data
}

\author{
Woong-Joo Whang \\ The Catholic University of Korea \\ Jin-woo Kwon ( $\sim$ krnjs99@catholic.ac.kr) \\ The Catholic University of Korea
}

\section{Research Article}

Keywords: prevalence, patients, surgery, largest

Posted Date: December 6th, 2021

DOI: https://doi.org/10.21203/rs.3.rs-1094457/v1

License: () (1) This work is licensed under a Creative Commons Attribution 4.0 International License. Read Full License 


\section{Abstract}

We identify the yearly trends in the prevalence of various ocular traumas in the Republic of Korea, and the effects of Covid-19. We recorded the yearly numbers of patients diagnosed with hyphema and those who underwent open reduction surgery because of orbital blowout fracture (BOF), primary closure of the cornea or sclera (PCCS), or intraocular foreign body (IOFB) removal. The incidence of closed globe injuries has decreased significantly over the past 10 years, while that of open globe injuries has not. The patients aged $\geq$ 60 years showed a significant increase in BOF surgery. Regarding the trend in PCCS, while other age groups showed significant decreases, the population aged $\geq 60$ years did not. In addition, the population aged $\geq 60$ years showed a significant increase in the incidence of IOFB. When the 2020 data were compared with those of 2019 , hyphema evidenced the largest decrease (27.02\%), especially in those aged $<20$ years $(54.33 \%)$. In terms of both BOF and IOFB, those aged $<20$ years showed the largest decreases $(28.85 \%$ and $47.93 \%$ respectively). In the Covid-19 era, ocular trauma fell markedly in those aged $<20$ years, perhaps because of school closures and reductions in outdoor activities.

\section{Introduction}

Ocular trauma is a major cause of serious visual impairment and blindness. ${ }^{1}$ Worldwide, 18 million people have monocular blindness from such injuries. ${ }^{2}$ Ocular trauma may cause irreversible visual impairment; the prevalence in younger patients is higher than that of other ocular diseases. ${ }^{2-5}$ Therefore, the socioeconomic cost is substantial. ${ }^{6}$

Ocular trauma can be classified as either closed globe injury or open globe injury (OGI), which is defined as a full-thickness disruption of the eye wall. To prevent severe intraocular infection, an OGI wound requires prompt evaluation and treatment such as primary closure of the cornea or sclera (PCCS) and/or intraocular foreign body (IOFB) removal. ${ }^{7,8}$

Although ocular trauma can cause serious complications, most are preventable. Thus, well-designed epidemiological studies identifying trends in the various types of traumas are essential to establish appropriate countermeasures. ${ }^{9,10}$ However, most previous reports have enrolled small populations or specific age groups, ${ }^{11,12}$ or the observation periods were too short to reveal trends. ${ }^{13}$ In addition, no report has explored the effects of Covid-19 on ocular trauma trends. Thus, we identified the epidemiological features of, and trends in, the major types of ocular trauma using the Korean National Health Insurance (NHI) claims database for the past 10 years. In addition, we explored the effects of Covid-19 on the trends.

\section{Results}

\section{Hyphema}

From 2011 to 2020, the annual incidence (cases per 100,000 person-years) of hyphema declined steadily and significantly from 18.77 to $7.10(\tau=-1.000, p<0.001)$. Males evidenced a higher incidence than females in all years. However, both male and female incidence declined significantly over time ( $\tau=-1.000, p<0.001$ and $\tau=-1.000, p<0.001$ respectively) (Figure $1 \mathrm{~A})$. By age, all age groups exhibited gradual and significant decreases over the 10 years (Table 1). This was most marked in those aged $<20$ years. When the 2020 data were compared to those of 2019 , hyphema showed the largest decrease $(27.02 \%)$ of all ocular traumas, particularly in those aged < 20 years (decline of $54.33 \%$ in 2020 [7.70] compared to the 2019 figure of 16.86) (Figure 2A). 
Table 1

Parameters obtained after Mann-Kendall analyses with yearly incidence rates for ocular traumas depending on age, 2011-2020.

\begin{tabular}{|c|c|c|c|c|c|c|c|c|c|c|c|c|}
\hline \multicolumn{4}{|c|}{ Hyphema } & \multicolumn{3}{|c|}{ Orbital blow-out fracture } & \multicolumn{3}{|c|}{$\begin{array}{l}\text { Primary closure of cornea } \\
\text { or sclera }\end{array}$} & \multicolumn{3}{|c|}{ Intraocular foreign body } \\
\hline $\begin{array}{l}\text { Age } \\
\text { (years } \\
\text { old) }\end{array}$ & $\begin{array}{l}\text { Sen's } \\
\text { slope }\end{array}$ & $\begin{array}{l}\text { Kendall's } \\
\tau\end{array}$ & $\begin{array}{l}\mathrm{P}- \\
\text { value }\end{array}$ & $\begin{array}{l}\text { Sen's } \\
\text { slope }\end{array}$ & $\begin{array}{l}\text { Kendall's } \\
\tau\end{array}$ & $\begin{array}{l}\mathrm{P} \text { - } \\
\text { value }\end{array}$ & $\begin{array}{l}\text { Sen's } \\
\text { slope }\end{array}$ & $\begin{array}{l}\text { Kendall's } \\
\tau\end{array}$ & $\begin{array}{l}\mathrm{P} \text { - } \\
\text { value }\end{array}$ & $\begin{array}{l}\text { Sen's } \\
\text { slope }\end{array}$ & $\begin{array}{l}\text { Kendall's } \\
\tau\end{array}$ & $\begin{array}{l}\text { P- } \\
\text { value }\end{array}$ \\
\hline$<20$ & -1.739 & -0.956 & $<0.001$ & -0.584 & -0.956 & $<0.001$ & -0.050 & -0.644 & 0.012 & 0.001 & 0.289 & 0.283 \\
\hline $\begin{array}{l}20 \leq \\
\text { and }< \\
40\end{array}$ & -0.931 & -1.000 & $<0.001$ & -0.785 & -0.867 & $<0.001$ & -0.053 & -0.733 & 0.004 & 0.000 & 0.022 & 1.000 \\
\hline $\begin{array}{l}40 \leq \\
\text { and }< \\
60\end{array}$ & -1.083 & -1.000 & $<0.001$ & -0.268 & -0.867 & $<0.001$ & -0.074 & -0.511 & 0.049 & -0.008 & -0.200 & 0.474 \\
\hline $60 \leq$ & -0.600 & -0.867 & $<0.001$ & 0.183 & 0.778 & 0.002 & 0.007 & 0.111 & 0.721 & 0.031 & 0.778 & 0.002 \\
\hline
\end{tabular}

\section{Orbital blowout fracture}

The annual incidence rates of blowout fracture (BOF) surgery decreased from 12.43 to 8.74 between 2011 and 2020; the trend was significant $(\tau=-1.000, p<0.001)$. By sex, males exhibited a higher incidence than females. However, both the male and female incidence decreased significantly $(\tau=-0.956, p<0.001$ and $\tau=-0.600, p=0.020)$ (Figure 1B). By age, while other age groups showed significant and gradual decreases, the population $\geq 60$ years had a significant increase (Table1). Those aged $\geq 20$ and $<40$ years exhibited the highest incidence; however, this gradually fell from 19.08 in 2011 to 13.45 in 2020 . When the 2020 data were compared to those of 2019, those aged < 20 years exhibited the greatest decrease from 6.57 to 4.91 (25.37\%) (Figure 2B).

\section{Open globe injury}

We found no significant trend in the annual overall incidence of PCCS $(\tau=-0.289, p=0.283)$. By sex, males evidenced a higher incidence than females. However, the male incidence decreased significantly $(\tau=-0.556, p=0.031)$; the female incidence increased, but not significantly $(\tau=0.289, p=0.283$ ) (Figure $1 C$ ). By age, those aged $\geq 60$ years exhibited the highest annual incidence throughout the observation period. The trend decreased significantly in younger patients, but increased in those aged $\geq 60$ years, although statistical significance was not attained (Table 1, Figure 2C). When the 2020 data were compared with those of 2019, those aged between 40 and 60 years evidenced the greatest fall, from 2.54 in 2019 to 2.01 in 2020 (21.15\%).

The annual incidence of IOFB removal increased from 0.34 to 0.46 (33.89\%) between 2011 and 2020, but statistical significance was not attained $(\tau=0.467, p=0.074)$. Males exhibited a higher incidence than females in all years. Males evidenced no significant trend ( $\tau=$ $0.378, p=0.152)$; females exhibited a significantly increasing trend ( $\tau=0.511, p=0.049$ ) (Figure 1D). By age, those aged 20 to 40 years evidenced the highest incidence in 2011, but those aged $\geq 60$ years the highest incidence in 2020 (Figure 2D). We found no significant trend for younger subjects, but those aged $\geq 60$ years exhibited a significantly increasing trend (Table 1). When the 2020 data were compared with those of 2019, the clearest difference was in those aged < 20 years, thus a decrease from 0.07 in 2019 to 0.03 in 2020 (47.93\%) (Figure 1D).

\section{Discussion}

This nationwide population-based study of ocular trauma revealed significantly decreasing trends in the incidence of hyphema and BOF, but no significant trends in the OGI incidence from 2011 to 2020. By age, the incidence of BOF and IOFB increased significantly in those aged $>60$ years, but not in younger subjects. Those aged $<20$ years manifested the greatest decrease in the incidence of most ocular traumas in 2020 compared to 2019.

Of the various ocular traumas, hyphema evidenced the greatest decrease from 2011 to $2020 .{ }^{14}$ Hyphema is the most common ocular trauma and exhibits a male and pediatric predominance, ${ }^{15,16}$ occurring principally in those aged $5-14$ years during participation in sport. ${ }^{17}$ We found that, although the prevalence was highest of all ocular traumas, the incidence decline was the fastest. This may reflect recent safety and preventive measures. Previous studies found that BOFs caused by assaults, traffic accidents, and sport peaked in those aged 20 to 40 years, ${ }^{17-19}$ as did we. BOF surgery gradually and significantly has decreased by $29.70 \%$ over the 10 years. However, 
the overall incidence of PCCS and IOFB did not change significantly over the decade. OGIs can cause permanent visual disturbance and any of endophthalmitis, traumatic cataracts, glaucoma, retinal detachment, and corneal opacity. ${ }^{20-22}$ Prevention of such injury is obviously most desirable.

Uniquely, we found that the incidence of the more serious ocular traumas, including BOF and IOFB, increased significantly in the older population. That of BOF has increased by $35.46 \%$ and that of IOFB by $58.95 \%$. As life expectancy increases and physiological aging slows, older adults are socially active or working. ${ }^{23}$ Although physiological functioning is better than in the past, some physical deterioration and reaction delay are inevitable. We infer that the increased ocular trauma rates are associated with increased social participation. As older adults are particularly prone to occupational accidents, workplace safety requires more attention. ${ }^{24,25}$

Covid-19 most affected the incidence of hyphema; in 2020, this was $27.02 \%$ less than in 2019. In contrast, the incidence of IOFB removal in 2020 was $1.75 \%$ greater than in 2019 . In those aged < 20 years, the hyphema incidence fell $54.33 \%$, the BOF incidence $25.37 \%$, and the IOFB removal incidence $47.93 \%$. Therefore, in the Covid-19 era, this age group exhibited the greatest declines in ocular traumas, perhaps reflecting school closures and reduced outdoor activities because of social distancing.

Our work had certain limitations. First, we could not identify the causes of trauma. Second, we inferred the incidence of BOF and OGI based on the numbers of surgeries. Thus, the incidence may have been underestimated.

In conclusion, in this nationwide population-based study of about 50 million Koreans supported by the NHI system, we explored the incidence and yearly trends of four major types of ocular trauma from 2011 to 2020 . The incidence of closed globe injuries decreased, but that of OGI did not. In addition, older adults have become more prone to serious ocular traumas. Given the school closures and social distancing in the era of Covid-19, ocular trauma in those aged $<20$ years decreased markedly.

\section{Methods}

\section{Study Design and Database}

We conducted a nationwide, population-based cross-sectional study using the Korean NHI claims database from January 2011 to December 2020. The study protocol was carried out in accordance with relevant guidelines and regulations. This is approved by the Institutional Review Board of of St. Vincent's Hospital. All Korean residents must be part of the NHI system; the database thus encompasses all medical claims nationwide. Informed consent was obtained from all subjects and legal guardians. We identified patients whose principal diagnoses or surgeries were attributable to hyphema (International Classification of Diseases, $10^{\text {th }}$ revision code H210), reduction of orbital BOF (S5211), PCCS (S5380), and IOFB removal (S4891 or S4892). The numbers of patients diagnosed or treated each year were recorded.

\section{Statistical Analysis}

We calculated incidence by year, sex, and age group, and compared the data. We used the census data of Statistics Korea to these ends. The Mann-Kendall test was employed to analyze incidence trends. All analyses were performed with the aid of R software version 3.6.1 (R Development Core Team, Vienna, Austria).

\section{Declarations}

\section{Competing interests}

The author(s) declare no competing interests.

\section{Data Availability}

The datasets generated during and/or analyzed during the current study are available from the corresponding author on reasonable request.

\section{References}

1. Feng, K. Epidemiology of Ocular Trauma in Anatomy and Examination in Ocular Trauma (ed. Yan, H.)105-122(Springer, 2019) 
2. Abbott, J. \& Shah, P. The epidemiology and etiology of pediatric ocular trauma. Surv. Ophthalmol, 58, 476-485 (2013).

3. Guly, C. M., Guly, H. R., Bouamra, O., Gray, R. H. \& Lecky, F. E. Ocular injuries in patients with major trauma. Emerg. Med. J, 23, 915917 (2006).

4. Wang, J. D. et al. Prevalence and incidence of ocular trauma in North China: the Beijing Eye Study. Acta Ophthalmol, 90, e61-67 (2012).

5. Yildiz, M., Kıvanç, S. A., Akova-Budak, B., Ozmen, A. T. \& Çevik, S. G. An Important Cause of Blindness in Children: Open Globe Injuries. J. Ophthalmol. 2016, 7173515 (2016)

6. Puodziuviene, E., Jokubauskiene, G., Vieversyte, M. \& Asselineau, K. A five-year retrospective study of the epidemiological characteristics and visual outcomes of pediatric ocular trauma. BMC Ophthalmol, 18, 10 (2018).

7. Duan, F. et al. Incidence and Risk Factors of Intraocular Foreign Body-Related Endophthalmitis in Southern China. J. Ophthalmol. 2018, 8959108 (2018)

8. Chaudhry, I. A. et al. Incidence and visual outcome of endophthalmitis associated with intraocular foreign bodies. Graefes Arch. Clin. Exp. Ophthalmol, 246, 181-186 (2008).

9. Zakrzewski, H., Chung, H., Sanders, E., Hanson, C. \& Ford, B. Evaluation of occupational ocular trauma: are we doing enough to promote eye safety in the workplace? Can. J. Ophthalmol, 52, 338-342 (2017).

10. Kuhn, F. Ocular traumatology: prevention, prevention, prevention. Graefes Arch. Clin. Exp. Ophthalmol, 248, 299-300 (2010).

11. Pandita, A. \& Merriman, M. Ocular trauma epidemiology: 10-year retrospective study. N. Z. Med. J, 125, 61-69 (2012).

12. Bućan, K. et al. Epidemiology of ocular trauma in children requiring hospital admission: a 16-year retrospective cohort study. J. Glob. Health, 7, 010415 (2017).

13. Voon, L. W., See, J. \& Wong, T. Y. The epidemiology of ocular trauma in Singapore: perspective from the emergency service of a large tertiary hospital. Eye (Lond), 15, 75-81 (2001).

14. Brandt, M. T. \& Haug, R. H. Traumatic hyphema: a comprehensive review. J. Oral Maxillofac. Surg, 59, 1462-1470 (2001).

15. Kennedy, R. H. \& Brubaker, R. F. Traumatic hyphema in a defined population. Am. J. Ophthalmol, 106, 123-130 (1988).

16. Spoor, T. C., Kwitko, G. M., O'Grady, J. M. \& Ramocki, J. M. Traumatic hyphema in an urban population. Am. J. Ophthalmol, 109, 2327 (1990).

17. Zafar, S. et al. Epidemiology of Hyphema-Related Emergency Department Visits in The United States Between 2006 and 2015. Ophthalmic Epidemiol, 26, 208-215 (2019).

18. Bartoli, D. et al. Retrospective analysis of 301 patients with orbital floor fracture. J. Craniomaxillofac. Surg, 43, 244-247 (2015).

19. Cruz, A. A. V. \& Eichenberger, G. C. D. Epidemiology and management of orbital fractures. Curr. Opin. Ophthalmol, 15, 416-421 (2004).

20. Thakker, M. M. \& Ray, S. Vision-limiting complications in open-globe injuries. Can. J. Ophthalmol, 41, 86-92 (2006).

21. Ahmed, Y., Schimel, A. M., Pathengay, A., Colyer, M. H. \& Flynn, H. W. Jr. Endophthalmitis following open-globe injuries. Eye (Lond), 26, 212-217 (2012).

22. Bojikian, K. D., Stein, A. L., Slabaugh, M. A. \& Chen, P. P. Incidence and risk factors for traumatic intraocular pressure elevation and traumatic glaucoma after open-globe injury. Eye (Lond), 29, 1579-1584 (2015).

23. Katagiri, K. \& Kim, J. H. Factors determining the social participation of older adults: A comparison between Japan and Korea using EASS 2012. PLoS One, 13, e0194703 (2018).

24. Batur, M. et al. Epidemiology of Adult Open Globe Injury. J. Craniofac. Surg, 27, 1636-1641 (2016).

25. Li, E. Y., Chan, T. C., Liu, A. T. \& Yuen, H. K. Epidemiology of Open-Globe Injuries in Hong Kong. Asia Pac. J. Ophthalmol. (Phila), 6, 54-58 (2017).

\section{Figures}




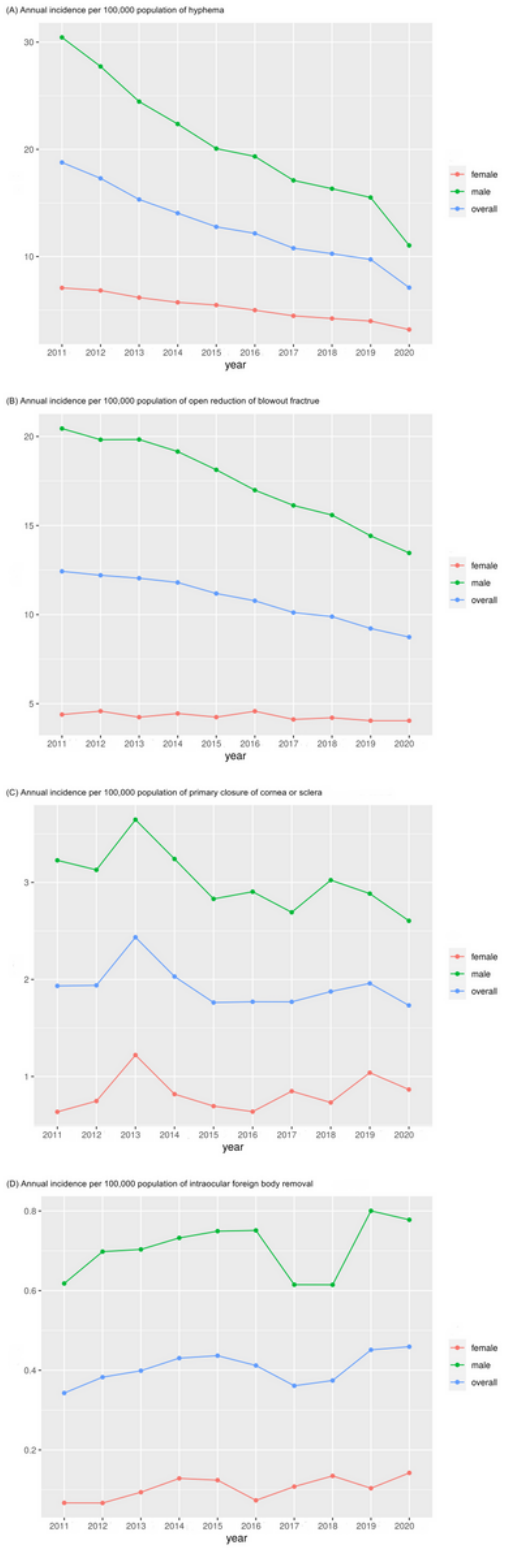

\section{Figure 1}

Yearly trends for different ocular traumas: Annual incidences 2011-2020. Compared to open globe injuries (C and D), hyphema (A) and orbital blowout fractures (B) declined significantly over time. Males were always more affected than females. 


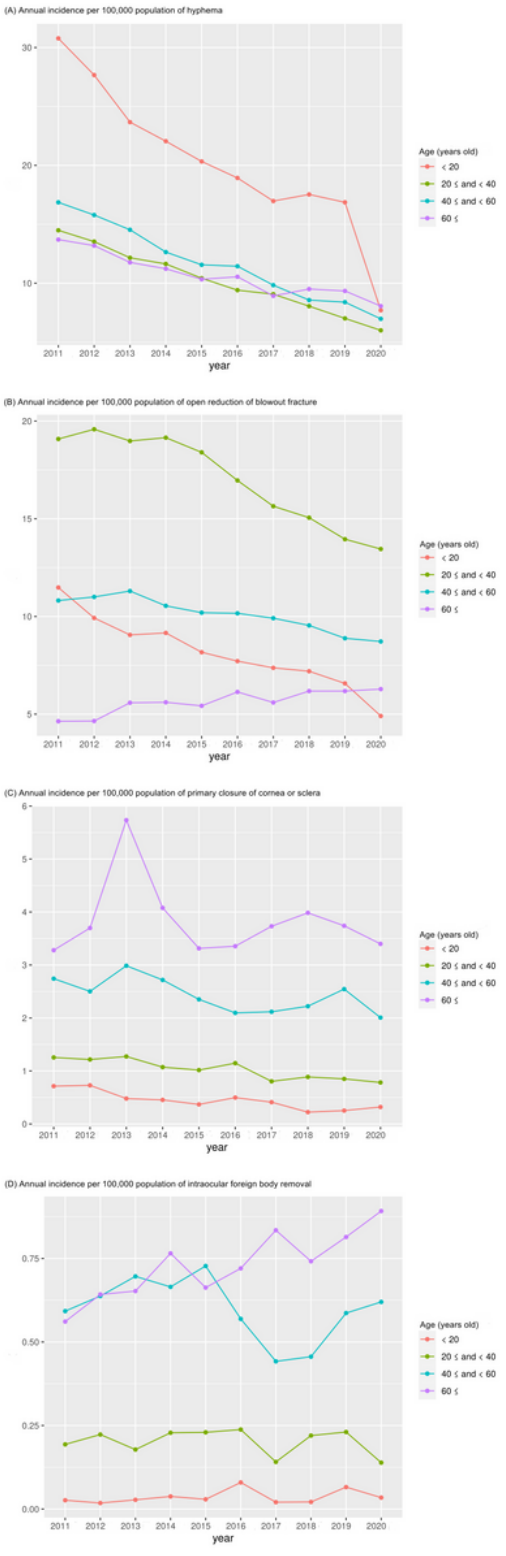

\section{Figure 2}

Yearly trends in the incidence of ocular traumas by age: 2011-2020. (A) The decreasing hyphema incidence was most marked in those aged $<20$ years. (B) Although younger subjects exhibited significant decreases in orbital blowout fracture, the reverse was true for those aged $>60$ years. (C) Although younger subjects exhibited significant decreases in primary closure of the cornea or sclera, those aged $\geq$ 60 years did not. (D) Compared to others, those aged $\geq 60$ years showed a significant and gradual increase in the intraocular foreign body removal rate. 